\title{
Editorial
}

ISSN: 2455-8702

\section{Ultrasound Imaging in Airway Management: A Boon?}

\author{
Rakesh Garg ${ }^{1 \star}$ and Anju Gupta ${ }^{2}$ \\ ${ }^{1}$ Assistant Professor, Department of Anaesthesiology, Pain and Palliative Care, Dr BRAIRCH, AIIMS, New Delhi, India \\ 2Assistant Professor, Department of Anaesthesiology, Delhi State Cancer Institute, Delhi, India
}

*Corresponding author: Rakesh Garg, Room No. 139, Ist floor, Department of Anaesthesiology, Pain and Palliative Care, Dr BRAIRCH, All India Institute of Medical Sciences, Ansari Nagar, New Delhi-110029, India, Tel: +91 9810394950; +91 9868398335; Email: drrgarg@hotmail.com

Received: September 03, 2014; Accepted: September 06, 2014; Published: September 08, 2014

Airway management is the basic skill acquired and mastered by anesthesiologist and is their prime responsibility. Difficulties in optimal airway management can lead to serious adverse effects and failure can even lead to mortality. Due to these reasons, diligent efforts are continuously being undertaken to improve the care in form of introduction of various guidelines, audits, safe monitoring standards and newer airway gadgets. Conventional imaging includes $\mathrm{x}$-rays, computed tomography (CT) or Magnetic resonance imaging (MRI). However these have risk of radiations hazards and do not provide real time imaging required during airway management. Ultrasound (US) is one such relatively recent adjunct to anaesthesiologist's armentarium. Since its inception in airway management, the list of applications of ultrasonography in perioperative, emergency and critical care settings is increasing exponentially. Its advantages include safety, simplicity, portability, non-invasiveness, cost effectiveness and reproducibility. Ample literature now exists to support its utility as well as efficacy.

Sound knowledge of the basic physics in relation to US, regional sono-anatomy and proper transducer selection is important to gain maximum advantage of the technique. Standard 7.5 $\mathrm{MHz}$ linear probe for visualisation of superficial structures and $5 \mathrm{MHz}$ curved array probe for deeper structures are used [1]. The image is built from reflected sound signals. Despite the fact that airway is filled with air which is a poor medium for US transmission, the superficial location of airway structures helps in sonographic visualisation. Infact, sonographic images of airway obtained using high frequency linear probe have higher resolution than CT or MRI [2].

US provide dynamic anatomical information. In a study by Erzi et al. [3] for prediction of difficult airway in morbidly obese patients, soft tissue thickness measured using US at the three levels on anterior aspect of trachea along with neck circumference $(>50 \mathrm{~cm})$ was found to correlate with difficult laryngoscopy [3]. In another study conducted in obese patients, authors found that hyomental distance ratio $>1.1$ on US (ratio of hyomental distance in neutral and hyperextended neck) predicted easy laryngoscopy [4]. Width of tongue base as measured by US and lateral pharyngeal wall thickness has also been found to correlate with the presence of obstructive sleep apnoea $[5,6]$.

US can reliably detect the presence of full stomach by measurement of cross sectional area of gastric antrum [7]. In addition, the nature of gastric contents (clear fluid, thick turbid or solid) can also be assessed
[8]. Another very useful application is identification of cricothyroid membrane prior to an anticipated difficult airway management [9]. This can provide an added safety by assisting emergency or elective placement of a transtracheal cricothyrotomy cannula to overcome a 'cannot ventilate cannot intubate' (CVCI) scenario. US can assist in performing superior laryngeal nerve blocks prior to a planned awake intubation $[10,11]$.

Prediction of endotracheal tube size by measuring subglottic diameter is useful application of US particularly in paediatric patients [12]. Prediction of diameter of left main stem bronchus (for placement of double lumen tube) was found to be quite reliable [13]. US guided measurements have shown good correlation with advance imaging techniques like CT and MRI $[12,13]$. US has also been utilized for determination of tracheal width and distance from the skin for prediction of tracheostomy tube size and shape [14].

Confirmation of endotracheal (ETT) placement is a promising application of US. Real-time visualisation of the endotracheal tube insertion, looking for lung-sliding and diaphragmatic movement bilaterally can help confirm the endotracheal intubation. Esophageal intubation can be reliably detected as a bright hyperechoic curved line on one side of and deeper to trachea [15]. Similarly, endobronchial intubation can be diagnosed by unilateral pleural and diaphragmatic movement. Filling the ETT cuff with fluid can help in locating its position [16]. In children, during real time visualisation of ETT with US, widening of vocal cords is seen as the ETT crosses them [17]. In a study by Adi et al. [18], authors concluded that bedside US to verify endotracheal tube location is feasible and can replace waveform capnography in centres without this facility. Pfeiffer et al. [19] showed that US confirmation of ETT placement is faster than standard method of auscultation with capnography. US confirmation of the ETT placement is potentially useful in noisy environment such as prehospital field situation, where auscultation may be difficult. In addition, in a cardiac arrest and other low cardiac output situation, where end tidal capnometry may not be very reliable, US can be a useful tool.

US can also be used to confirm correct laryngeal mask airway (LMA) placement and rule out causes of inadequate ventilation [20]. LMA cuff (inflated with fluid) should be visualized equally on both sides of larynx for proper seal. Grading of LMA placement thus obtained using US is more convenient as compared to fiberoptic examination with good correlation of the results [20]. 
US guided percutaneous dilatational tracheostomy (PDT) is increasingly being advocated. It permits visualisation of pretracheal blood vessels and selection of puncture site [21]. It decreases adverse effects related to PDT e.g. cranial misplacement, major haemorrhage, posterior tracheal wall puncture and injury to thyroid isthmus [2123]. Hypercapnia associated with FOB guided PDT can also be avoided with US guided procedure [24]. Real time visualisation of the needle path and guide wire placement using linear array probe may increase the success with US guided PDT [25].

Post extubation stridor can be reliably predicted in intubated patients by measuring the width of air column after deflating the ETT cuff [26]. An air column width of less than $4.5 \pm 0.8 \mathrm{~mm}$ was found to be associated with stridor. In addition to assessment and intervention, US has found its place in diagnosis of various conditions that can have implication for airway management e.g. vocal cord malfunction, [27] swallowing abnormalities, [28] sialolithiasis, [29] supraglottic hemangiomas, [30] respiratory papillomatosis [31], laryngeal stenosis, [32] Zenker's diverticulum, [33] maxillary sinusitis [34] etc to name a few.

Limitation of sonography like any other skill based technique is that its use is operator dependent and requires initial training to become proficient in its use. Though encouraging evidence exists, it is not robust enough to prompt a change in standard practise at present. At present, US can be viewed as a complement to other monitoring and imaging modalities rather than a replacement. Recent developments in sonography technology like pocket sized smart phone based system can widen the horizon for its application even in remote areas [35].

To conclude, ultrasonography is turning out to be a boon to managers of airway. With better accessibility, familiarity and further improvement in technology, its use in airway management may well become a rule rather than exception in future.

\section{References}

1. Kundra P, Mishra SK, Ramesh A (2011) Ultrasound of the airway. Indian $J$ Anaesth 55: 456-462.

2. Beale TJ, Rubin JS (2008) In: Orloff LA (ed) Laryngeal ultrasonography Plural Publishing, San Diego, 183-202.

3. Ezri T, Gewurtz G, Sessler DI, Medalion B, Szmuk P, et al. (2003) Prediction of difficult laryngoscopy in obese patients by ultrasound quantification of anterior neck soft tissue. Anaesthesia 58: 1111-1114.

4. Wojtczak JA (2012) Submandibular sonography: assessment of hyomental distances and ratio, tongue size, and floor of the mouthmusculature using portable sonography. J Ultrasound Med 31: 523-528.

5. Lahav Y, Rosenzweig E, Heyman Z, Doljansky J, Green A, et al. (2009) Tongue base ultrasound: a diagnostic tool for predicting obstructive sleep apnea. Ann Otol Rhinol Laryngol 118: 179-184.

6. Liu KH, Chu WC, To KW, Ko FW, Tong MW, et al. (2007) Sonographic measurement of lateral parapharyngeal wall thickness in patients with obstructive sleep apnea. Sleep 30: 1503-1508.

7. Jacoby J, Smith G, Eberhardt M, Heller M (2003) Bedside ultrasound to determine prandial status. Am J Emerg Med 21: 216-219.

8. Shiver SA, Blaivas M (2004) Gastric outlet obstruction secondary to linitis plastica of the stomach as shown on transabdominal sonography. $J$ Ultrasound Med 23: 989-992.
9. Orr JA, Stephens RS, Mitchell VM (2007) Ultrasound-guided localisation of the trachea. Anaesthesia 62: 972-973.

10. Manikandan S, Neema PK, Rathod RC (2010) Ultrasound-guided bilateral superior laryngeal nerve block to aid awake endotracheal intubation in a patient with cervical spine disease for emergency surgery. Anaesth Intensive Care 38: 946-948.

11. Kaur B, Tang R, Sawka A, Krebs C, Vaghadia H (2012) A method for ultrasonographic visualization and injection of the superior laryngeal nerve: volunteer study and cadaver simulation. Anesth Analg 115: 1242-1245.

12. Shibasaki M, Nakajima Y, Ishii S, Shimizu F, Shime N, et al. (2010) Prediction of pediatric endotracheal tube size by ultrasonography. Anesthesiology 113 : 819-824.

13. Sustiæ A, Miletiæ D, Protiæ A, Ivanciæ A, Cicvariæ T (2008) Can ultrasound be useful for predicting the size of a left double-lumen bronchial tube? Tracheal width as measured by ultrasonography versus computed tomography. J Clin Anesth 20: 247-252.

14. Hardee PS, Ng SY, Cashman M (2003) Ultrasound imaging in the preoperative estimation of the size of tracheostomy tube required in specialised operations in children. Br J Oral Maxillofac Surg 41: 312-316.

15. Milling TJ, Jones M, Khan T, Tad-y D, Melniker LA, et al. (2007) Transtracheal 2-d ultrasound for identification of esophageal intubation. J Emerg Med 32: $409-414$.

16. Hatfield A, Bodenham A (1999) Ultrasound: an emerging role in anaesthesia and intensive care. Br J Anaesth 83: 789-780.

17. Marciniak B, Fayoux P, Hébrard A, Krivosic-Horber R, Engelhardt T, et al. (2009) Airway management in children: ultrasonography assessment of tracheal intubation in real time? Anesth Analg 108: 461-465.

18. Adi O, Chuan TW, Rishya M (2013) A feasibility study on bedside upper airway ultrasonography compared to waveform capnography for verifying endotracheal tube location after intubation. Crit Ultrasound J 5: 7.

19. Pfeiffer P, Bache S, Isbye DL, Rudolph SS, Rovsing L, et al. (2012) Verification of endotracheal intubation in obese patients - temporal comparison of ultrasound vs. auscultation and capnography. Acta Anaesthesiol Scand 5: 571-576

20. Gupta D, Srirajakalidindi A, Habli N, Haber H (2011) Ultrasound confirmation of laryngeal mask airway placement correlates with fiberoptic laryngoscope findings. Middle East J Anesthesiol 21: 283-287.

21. Hatfield A, Bodenham A (1999) Portable ultrasonic scanning of the anterior neck before percutaneous dilatational tracheostomy. Anaesthesia 54: 660 663.

22. Sustic A, Kovac D, Zgaljardić Z, Zupan Z, Krstulović B (2000) Ultrasoundguided percutaneous dilatational tracheostomy: a safe method to avoid cranial misplacement of the tracheostomy tube. Intensive Care Med 26: 1379-1381.

23. Hatfield A, Bodenham A (1999) Portable ultrasonic scanning of the anterior neck before percutaneous dilatational tracheostomy. Anaesthesia 54: 660-663.

24. Reilly PM, Sing RF, Giberson FA, Anderson HL 3rd, Rotondo MF, et al. (1997) Hypercarbia during tracheostomy: a comparison of percutaneous endoscopic, percutaneous Doppler, and standard surgical tracheostomy. Intensive Care Med 23: 859-864.

25. Rajajee V, Fletcher JJ, Rochlen LR, Jacobs TL (2011) Real-time ultrasoundguided percutaneous dilatational tracheostomy: a feasibility study. Crit Care 15: R67.

26. Ding LW, Wang HC, Wu HD, Chang CJ, Yang PC (2006) Laryngeal ultrasound: a useful method in predicting post-extubation stridor. A pilot study. Eur Respir J 27: 384-389.

27. Friedman EM (1997) Role of ultrasound in the assessment of vocal cord function in infants and children. Ann Otol Rhinol Laryngol 106: 199-209. 
28. Shawker TH, Sonies B, Hall TE, Baum BF (1984) Ultrasound analysis of tongue, hyoid, and larynx activity during swallowing. Invest Radiol 19: 82-86.

29. Suhitharan T, Seevanayagam S, Parker F, Teoh W (2013) Acute unilatera submandibular gland swelling associated with the laryngeal mask airway. Singapore Med J 54: 236-239.

30. Rossler L, Rothoeft T, Teig N, Koerner-Rettberg C, Deitmer T, et al. (2011) Ultrasound and colour Doppler in infantile subglottic haemangioma. Pediatr Radiol 41: 1421-1428.

31. Bryson PC, Leight WD, Zdanski CJ, Drake AF, Rose AS (2009) High resolution ultrasound in the evaluation of pediatric recurrent respiratory papillomatosis. Arch Otolaryngol Head Neck Surg 135: 250-253.
32. Garel C, Contencin P, Polonovski JM, Hassan M, Narcy P (1992) Laryngeal ultrasonography in infants and children: a new way of investigating. Normal and pathological findings. Int J Pediatr Otorhinolaryngol 23: 107-115.

33. Lixin J, Bing H, Zhigang W, Binghui Z (2011) Sonographic diagnosis features of Zenker diverticulum. Eur J Radiol 80: 13-19.

34. Butcher C (2010) Ultrasound evaluation of the neck and upper respiratory system. In: Levitov A, Mayo P, Slonim A, editors. Critical Care Ultrasonography, 1 st ed. USA: McGraw-Hill 235-238.

35. Wojtczak J, Bonadonna P (2013) Pocket mobile smart phone system for the point-of-care submandibular ultrasonography. Am J Emerg Med 31: 573577. 